\title{
The Alpha-2 Adrenergic Agonist Guanfacine Improves Memory in Aged Monkeys Without Sedative or Hypotensive Side Effects: Evidence for Alpha-2 Receptor Subtypes
}

\author{
Amy F. T. Arnsten, Jing Xia Cai," and Patricia S. Goldman-Rakic \\ Section of Neuroanatomy, Yale Medical School, New Haven, Connecticut 06510
}

The present study attempted to identify an alpha-2 agonist that could improve working memory in aged nonhuman primates without the marked hypotensive and sedative side effects produced by clonidine. Toward this end, the hypotensive, sedative, and memory-altering properties of the alpha-2 adrenergic agonists, B-HT920 and guanfacine, were compared with clonidine's effects in 9 aged rhesus monkeys. Memory capacity was assessed by a variable delay, spatial delayed response paradigm that requires the animal to remember information over short temporal intervals and to update this information on every trial. B-HT920 was found to produce a dose-response profile qualitatively similar to, but weaker than, clonidine: low doses impaired memory and began to lower blood pressure and produce sedation, while high doses improved memory. In contrast, guanfacine produced a dose-response profile opposite to that seen with clonidine: low doses improved memory without inducing hypotension or sedation, while the memory-impairing, hypotensive, and sedating properties of the drug were observed at higher doses. The potency of the 3 agonists to lower blood pressure was clonidine $=$ B-HT920 $>$ guanfacine; sedation was affected in the order clonidine > B-HT920 > guanfacine; for memory impairment, as measured by performance on the delayed response task, the rank order potency was clonidine $>$ B-HT920 > guanfacine, while for memory improvement it was guanfacine $>$ clonidine $>$ B-HT920. These differences in rank order potency are consistent with the recent proposal of alpha-2 receptor subtypes, a rauwolscine-sensitive site (Rs) that binds clonidine > B-HT920 > guanfacine and a rauwolscine-insensitive site $(\mathrm{Ri})$ that binds guanfacine $>$ clonidine > B-HT920 (Boyajian and Leslie, 1987). The data suggest that the hypotensive, sedating, and memory-impairing effects of alpha-2 agonists may be due to actions at one subtype of receptor (Rs), while the memory-enhancing effects of these drugs may result from actions at another alpha-2 receptor subtype, the Ri site. The ability of low doses

\footnotetext{
Received Dec. 23, 1987; revised Mar. 29, 1988; accepted Apr. 1, 1988.

We are grateful to Ms. Linda Ladewig for her assistance in testing aged monkeys and to Ms. Tracy Contant for her help in all aspects of this research. This work was supported by PHS Grant AG06036 and MH38546 and Faculty Scholar Award 85-010 from the Alzheimer's Disease and Related Disorders Association.

Correspondence should be addressed to Dr. A. F. T. Arnsten, Section of Neuroanatomy, P.O. Box 3333, Yale Medical School, 333 Cedar Street, New Haven, CT 06510-8001.

${ }^{2}$ Present address: Kunming Institute of Zoology, Academia Sinica, Kunming, Yunnan, Peoples Republic of China.

Copyright (C) 1988 Society for Neuroscience $0270-6474 / 88 / 114287-12 \$ 02.00 / 0$
}

of guanfacine to improve memory without inducing hypotension or sedation indicates that this agonist may be an excellent candidate for treating memory disorders in man.

Over the past decades, a growing body of work has established that norepinephrine (NE) plays an important role in the performance of cognitive functions in a variety of species (e.g., Foote et al., 1975; Stein et al., 1975; Segal and Bloom, 1976; Oke and Adams, 1978; McEntee and Mair, 1980; Carli et al., 1983; McGaugh et al., 1984; Leslie et al., 1985). Recently, the alpha- 2 adrenergic agonist clonidine has been shown to improve performance on the delayed response task, a test of spatial working memory, in aged rhesus monkeys with naturally occurring memory impairment (Arnsten and Goldman-Rakic, 1985). In general, improvement occurred only in the high-dose range (e.g., $50 \mu \mathrm{g} / \mathrm{kg}$ ), whereas low doscs $(<10 \mu \mathrm{g} / \mathrm{kg})$ impaired memory. The finding that clonidine's ability to improve memory was reversed by the alpha- 2 antagonist yohimbine but not by the alpha-1 antagonist prazosin indicated that clonidine acted at alpha-2 receptors (Arnsten and Goldman-Rakic, 1985). Results from young monkeys with localized 6-hydroxydopamine (6OHDA) lesions further suggested that clonidine improved memory through actions at postsynaptic alpha- 2 receplors in the principal sulcal region of the prefrontal cortex, the area of cortex that is critical for delayed response performance (Arnsten and Goldman-Rakic, 1985). As prefrontal cortex is particularly vulnerable to catecholamine loss with advancing age (GoldmanRakic and Brown, 1981), Arnsten and Goldman-Rakic hypothesized that clonidine in high doses may replace lost NE in the prefrontal cortex and thus restore mnemonic function. Conversely, it is possible that the impairments in memory produced by low doses of clonidine result from inhibitory actions on NE neurons at presynaptic alpha-2 receptors (Cedarbaum and Aghajanian, 1976), actions that would exaggerate the naturally occurring loss of NE and exacerbate cognitive deficits.

Clonidine has numerous effects in addition to altering cognitive function, 2 of the most prominent being its ability to lower blood pressure and induce sedation (Dollery et al., 1976). The hypotensive and sedative effects of clonidine begin to appear at low doses, the clinical dose range for treating hypertension being approximately $1-10 \mu \mathrm{g} / \mathrm{kg}$. With increasing dose, clonidine's hypotensive and sedative effects become progressively more marked in man and monkey, and in the high-dose range $(50 \mu \mathrm{g} / \mathrm{kg})$ where memory improvement is observed in the aged monkeys, sedation and hypotension are severe. These serious side effects have impeded clinical tests of clonidine for the treatment of memory disorders such as Alzheimer's disease, 
in which cognitive deterioration is associated with profound loss of NE (e.g., Forno, 1978; Cross et al., 1981). Thus, it would be clinically important to identify an alpha-2 agonist with less sedating and hypotensive properties than clonidine.

The present study attempted to identify such an agonist by comparing the effects of the alpha-2 agonists B-HT920 and guanfacine with those of clonidine on blood pressure, sedation, and memory, the latter as measured by performance on the delayed response task, in 9 aged rhesus monkeys. B-HT920 and guanfacine were chosen because they have greater alpha-2/alpha-1 selectivity than does clonidine (Doxey, 1979; Kobinger, 1986). In addition, B-HT920 and guanfacine are known to have very different affinities for 2 recently proposed subtypes of alpha- 2 receptors, a rauwolscine-sensitive site, designated $R s$, and a rauwolscine-insensitive site, designated $\mathrm{Ri}$ (Boyajian and Leslie, 1987; Boyajian et al., 1987). Guanfacine is selective for the Ri site, B-HT920 is selective for but relatively weak at the Rs site, while clonidine has high affinity for both sites but has slightly higher affinity at the Rs than at the Ri site (Boyajian and Leslie, 1987). The following study suggests that clonidine's ability to improve memory is associated with actions at one of the proposed subtypes, the Ri site, while the hypotensive, sedative, and memory-impairing effects of clonidine may be related to actions at the Rs site. In addition, this study identifies guanfacine as an alpha-2 agonist that is able to improve memory without inducing hypotensive or sedative side effects in the aged nonhuman primate.

\section{Materials and Methods}

Subjects. The animals used in this study were 9 female rhesus monkeys (Macaca mulatta) ranging in age from about 17 to over 30 years. As actual birth dates were unavailable, ages were estimated on the basis of prior breeding and behavioral testing records, as well as on dental records and general appearance. Rhesus monkeys in captivity have been reported to live until 20-25 years and occasionally longer (Lapin et al., 1979).

Delayed response testing. Cognitive testing occurred in a Wisconsin General Test Apparatus (WGTA) situated in a sound-attenuating room. Background masking noise ( $60 \mathrm{~dB}$, wideband) also was used to minimize auditory distractions. Animals were always tested at the same time of day immediately prior to feeding. Given the fragile health of aged monkeys, the animals were maintained on full diets; no problems with motivation were observed using these dietary conditions.

The aged monkeys initially were trained on the 2 -well spatial delayed response task for 1000 trials. This test measures the mnemonic process of representational or working memory (Goldman-Rakic, 1987; Friedman and Goldman-Rakic, 1988), a process that is fundamentally decimated in Alzheimer's disease (Corkin, 1982). In delayed response, the monkey watches as the experimenter baits 1 of 2 foodwells. The foodwells are then covered with identical cardboard plaques, and an opaque screen is lowered between the animal and the test tray for a specified delay. At the end of this delay, the screen is raised and the animal is allowed to choose. Reward is quasi-randomly distributed between the left and right wells over the 30 trials that make up a daily test session. During the initial training phase, delays were held constant during a daily test session and were gradually increased according to a stepwise procedure over the 1000 trials.

Following the 1000 trials, the animals were prepared for drug testing. In order to observe the effects of each drug on memory capacity, animals were trained on a variable delayed response task in which the delays were varied between less than $1 \mathrm{sec}$ (" 0 " sec) and the temporal interval that yielded chance performance for each animal within a session. Five different delay lengths were quasi-randomly distributed over the 30 trials that made up the daily test session. For example, the range of delays for monkey \#447 was " 0, , $9,18,27$, and $36 \mathrm{sec}$; animals with better memory required longer delays (e.g., "0," $15,30,45$, and $60 \mathrm{sec}$ ). All aged animals performed perfectly at " 0 " sec delays and exhibited increasing difficulty with progressively longer delays, a pattern consistent with memory impairment. Delays were adjusted until the animals exhibited stable baseline performance of approximately $67 \%$ correct. Over the two and a half year duration of this study, the average baseline (saline) performance of the 9 aged monkeys was $67.9 \pm 0.5 \%$ correct. The stability of baseline performance is indicated by the small variability about this mean for any given animal (SEMs ranged from $\pm 0.8-1.4 \%$; the average SEM was $\pm 1.1 \%$ ). Animals were tested twice a week, with 3-4 d separating test sessions.

Sedation assessment. Sedation was rated using a 5-point scale, where $0=$ normal level of arousal, $\mathrm{I}=$ quieter than usual, $\mathrm{II}=$ sedated (drooping eyelids, slowed movements), III $=$ intermittent sleeping, and IV $=$ too sedated to test.

Drug administration. Nine aged monkeys were tested on clonidine and guanfacine; 6 of these monkeys also were tested on B-HT920. All drug doses were equimolar and are expressed as equivalent doses of clonidine (for example, $0.053 \mathrm{mg} / \mathrm{kg}$ guanfacine is equivalent to 0.05 $\mathrm{mg} / \mathrm{kg}$ clonidine). Drug solutions were made up fresh each day under sterile conditions. Drugs were diluted in sterile saline and injected intramuscularly $15 \mathrm{~min}$ (all drugs) or $2 \mathrm{hr}$ (guanfacine) prior to delayed response testing. Generally, a single dose of an agonist was administered each week; extended washout periods were necessary for guanfacine because of the long-lasting effects of this treatment (see below). The order of drug and dose administration was determined quasi-randomly. The experimenter testing the animal was unaware of the drug treatment conditions.

Idazoxan reversal of the guanfacine response. In order to insure that guanfacine's effects resulted from actions at alpha- 2 receptors, the alpha-2 antagonist idazoxan was coadministered with guanfacine 15 min prior to testing in 5 aged monkeys. Idazoxan was selected because of its high affinity for both of the proposed alpha-2 receptor subtypes (Boyajian and Leslie, 1987). As idazoxan is unstable in solution, the drug was diluted immediately prior to injection. The effects of guanfacine + idazoxan were contrasted with the effects of guanfacine + saline, and both of these treatments were compared with saline + saline control performance. The dose of idazoxan was $0.1 \mathrm{mg} / \mathrm{kg}$; the dose of guanfacine was that which produced optimal improvement for each individual animal.

Guanfacine was kindly provided by A. H. Robins (Richmond, VA), licensee of Sandoz Pharmaceuticals (East Hanover, NJ), clonidine and B-HT 920 by Boehringer Ingelheim (Ridgefield, CT), and idazoxan by Reckitt and Colman (Kingston-upon-Hull, England).

Data analysis. Delayed response performance on the drug was compared with matched placebo control (saline) for the same week: the number of trials correct on drug was subtracted from the number of trials correct on saline; this difference score then was multiplied by $3.3 \%$, as each trial constitutes $3.3 \%$ of the total number of trials. In other words, drug effect was expressed as the percentage change from placebo control [(number correct drug - number correct placebo) $\times 3.3 \%$ ]. As the animals served as their own controls, statistical analyses employed repeated-measures designs: paired $t$ test (also called dependent $t$ test or $t$-dep); 1 -way analysis of variance with repeated measures (1-ANOVAR); and 2-way analysis of variance with repeated measures (2-ANOVAR). Differences in sedation score data were assessed using a nonparametric, repeated-measures analysis (Wilcoxon test). Statistical analysis was conducted on a Macintosh computer using a statistics package (Systat).

Blood pressure study. In order to mcasurc blood pressurc in the awake, behaving monkey, 3 aged animals were adapted to primate chair restraint for several weeks. Blood pressure was measured using a pediatric digital blood pressure monitor. Each day the animals were chaired and then immediately injected with drug or saline. Fifteen minutes later, 3 blood pressure measurements were taken. The animal was then tested on delayed response for approximately $30 \mathrm{~min}$. Following cognitive testing, 3 more blood pressure measurements were taken before the monkey was returned to its home cage. The average blood pressure response before and after cognitive testing was calculated; drug response was compared with previous response on saline. Drug administration was initiated only after stable blood pressure and delayed response baselines were obtained.

\section{Results}

Clonidine response in aged monkeys

Clonidine significantly altered delayed response performance [1ANOVA-R, $F(3,24)=7.28, p<0.001]$, producing a dose- 
response profile identical to that reported previously (Arnsten and Goldman-Rakic, 1985). As seen in Figure 1, low doses of clonidine produced a small but significant impairment in delayed response performance $(0.0001 \mathrm{mg} / \mathrm{kg}$ clonidine vs saline: $t$-dep $=3.68, p<0.006$ ). These deleterious effects were often observed in the middle delay range for each animal, as floor effects generally prevented further decline in performance at the longest delays. Performance at " 0 "' sec delay was rarely altered, indicating that errors were not due to inattention during baiting of the foodwells. In contrast, higher clonidinc doses substantially improved performance (Fig. 1; $0.05 \mathrm{mg} / \mathrm{kg}$ clonidine vs saline: $t$-dep $=3.73, p<0.006$ ). As observed in the previous study (Arnsten and Goldman-Rakic, 1985), the beneficial effects of clonidine were most apparent at the longest delays, for which there was the greatest room for improvement. Following an optimal dose of clonidine, many animals were able to achieve near-perfect performance. At still higher doses, delayed response performance began to deteriorate, presumably due to clonidine's severe sedative effects, and many animals were too sedated to complete a test session.

Clonidine's sedative effects first became apparent in many animals at doses as low as $0.001-0.01 \mathrm{mg} / \mathrm{kg}$ (Fig. 1; median sedation score for $0.01 \mathrm{mg} / \mathrm{kg}=\mathrm{I}$, quieter than usual; $0.01 \mathrm{mg}$ / $\mathrm{kg}$ clonidine vs saline: Wilcoxon $p<0.07$ ). As dose was increased, the animals began to exhibit signs of sedation (drooping eyelids, slowed movements), and with still higher doses displayed bouts of intermittent sleeping (e.g., median sedation score for $0.05 \mathrm{mg} / \mathrm{kg}=\mathrm{III} ; 0.05 \mathrm{mg} / \mathrm{kg}$ clonidine vs saline: Wilcoxon $p<0.008$ ). At the highest doses tested, the animals were too sedated to test (sedation score of IV). Most animals were able to perform above baseline levels even when displaying sedation scores of II or III.

The hypotensive effects of clonidine were measured in 3 chairrestrained aged monkeys. Small decreases in systolic blood pressure appeared even at very low doses $(0.0001-0.001 \mathrm{mg} / \mathrm{kg})$ (Fig. 1). At $0.01 \mathrm{mg} / \mathrm{kg}$, the average drop in blood pressure was $>30 \mathrm{~mm}$, and by $0.05 \mathrm{mg} / \mathrm{kg}$, the hypotensive effects of clonidine were so severe that blood pressure was no longer measurable (below 70/70; >50 mm drop). These hypotensive effects were evident 15 min after injection, as well as after delayed response testing, approximately $1 \mathrm{hr}$ after injection.

\section{$B$-HT920 response in aged monkeys}

B-HT920 significantly altered delayed response performance [1ANOVA-R, $F(3,15)=4.79, p<0.016]$. The dose-response profile produced by this agonist was qualitatively similar to clonidine, impairing performance at low doses and improving performance at higher doses [Fig. 2; 2-ANOVA-R, clonidine vs B-HT920 drug $\times$ dose interaction not significant: $F(3,15)=$ $2.11, p<0.15]$. However, B-HT920 was weaker than clonidine, and significantly higher doses of B-HT920 were needed to produce maximal impairment or improvement in delayed response performance (Table 1). The delayed response performance of aged monkey \#445 (Fig. 3, upper-right-hand graph) clearly shows that higher doses of B-HT920 than clonidine were needed to produce comparable changes in behavior. Whereas $0.001 \mathrm{mg} /$ $\mathrm{kg}$ clonidine was sufficient to reduce performance by $15 \%, 10$ times more B-HT920 was needed to induce a similar degree of impairment. Likewise, $0.04 \mathrm{mg} / \mathrm{kg}$ clonidine produced optimal improvement in performance; comparable improvement was found with $0.06 \mathrm{mg} / \mathrm{kg} \mathrm{B-HT920.} \mathrm{Similar} \mathrm{differences} \mathrm{in} \mathrm{agonist}$
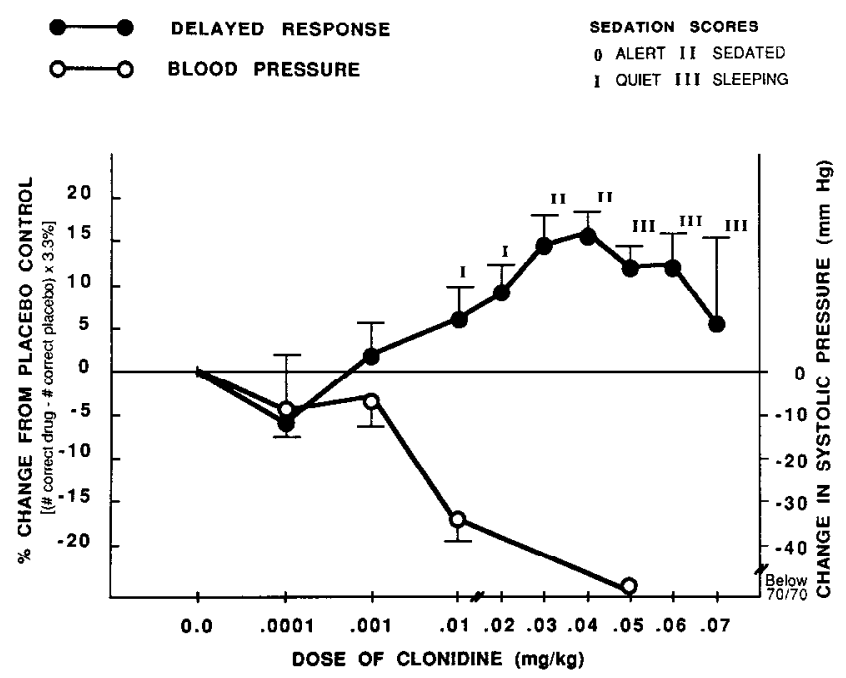

Figure 1. Effects of clonidine on delayed response performance (solid circles), systolic blood pressure (open circles), and sedation (scores as indicated; no number signifies a sedation score of zero). Data points represent means \pm SEM for 9 aged monkeys (delayed response and sedation) or 3 aged monkeys (blood pressure).

potency were seen with the 5 other aged monkeys who received clonidine and B-HT920, e.g., monkey \#113 (Fig. 4, middle and bottom graphs).

B-HT920 was weaker than was clonidine in producing sedation (Figs. 2-4). Thus, the average lowest dose to produce a sedation score of II was $0.03 \pm 0.008 \mathrm{mg} / \mathrm{kg}$ for clonidine and $0.053 \pm 0.006 \mathrm{mg} / \mathrm{kg}$ for B-HT920 $(t$-dep $=5.53, d f=5, p<$ $0.005)$. As tolerance to the sedative effects of alpha- 2 agonists can occur, the sedation score results were generally more variable than the delayed response performance or blood pressure data.

B-HT920 was equipotent to clonidine in its ability to lower blood pressure (Figs. 2, 3). Both drugs began to decrease systolic blood pressure in the $0.0001-0.001 \mathrm{mg} / \mathrm{kg}$ range, produced marked hypotension at $0.01 \mathrm{mg} / \mathrm{kg}$, and lowered blood pressure below $70 / 70 \mathrm{~mm}$ at $0.05 \mathrm{mg} / \mathrm{kg}$.

\section{Guanfacine response in aged monkeys}

The effects of low to moderate doses of guanfacine on working memory produced a dose-response profile that was opposite to that found with clonidine [Fig. 5; 2-ANOVA-R clonidine vs guanfacine, drug $\times$ dose interaction: $F(3,24)=8.07, p<0.001]$. Guanfacine significantly altered delayed response performance [1-ANOVA-R, $F(3,24)=7.47, p<0.001$ ]; however, in direct contrast to clonidine, low doses significantly improved performance, while higher doses impaired performance [Fig. 5; 0.0001 or $0.001 \mathrm{mg} / \mathrm{kg}$ guanfacine vs saline significantly improved performance: $t$-dep $=3.6, p<0.007$, and $t$-dep $=5.4, p<0.001$,

Table 1. Optimal dosage ( $\mathrm{mg} / \mathrm{kg}$ ) for producing maximal impairment or improvement of delayed response performance

\begin{tabular}{lll} 
Drug & Impairing & Improving \\
\hline Clonidine & $0.00055 \pm 0.00026$ & $0.029 \pm 0.009$ \\
B-HT920 & $0.00750 \pm 0.00250^{a}$ & $0.054 \pm 0.007^{a}$
\end{tabular}

Values represent means \pm SEM for 6 aged monkeys.

${ }^{a} p<0.05, t$-dep comparing equivalent doses of clonidine and B-HT920. 


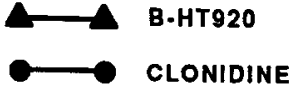

LONIDINE
SEDATION SCORES

- ALERT II SEDATED

I QUIET III SLEEPING

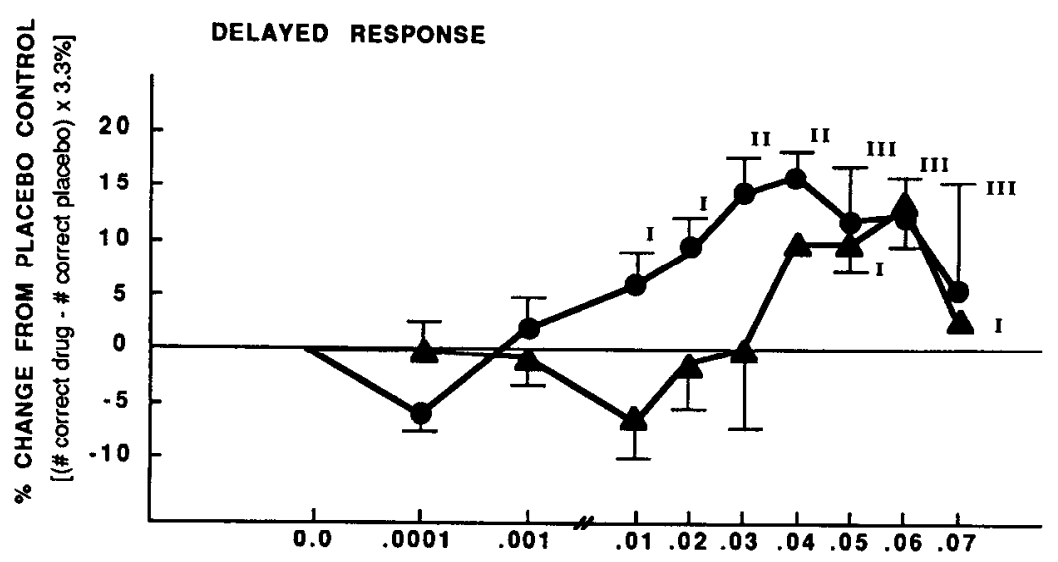

Figure 2. Effects of clonidine (circles, $n=9$ ) and B-HT920 (triangles, $n=6$ ) on delayed response performance and sedation (top graph) and systolic blood pressure (lower graph, $n=3$ ). Doses of B-HT920 are equimolar clonidine dosage (e.g., $0.053 \mathrm{mg} / \mathrm{kg}$ B-HT $920=0.05$ $\mathrm{mg} / \mathrm{kg}$ clonidine). Data points represent means \pm SEM.

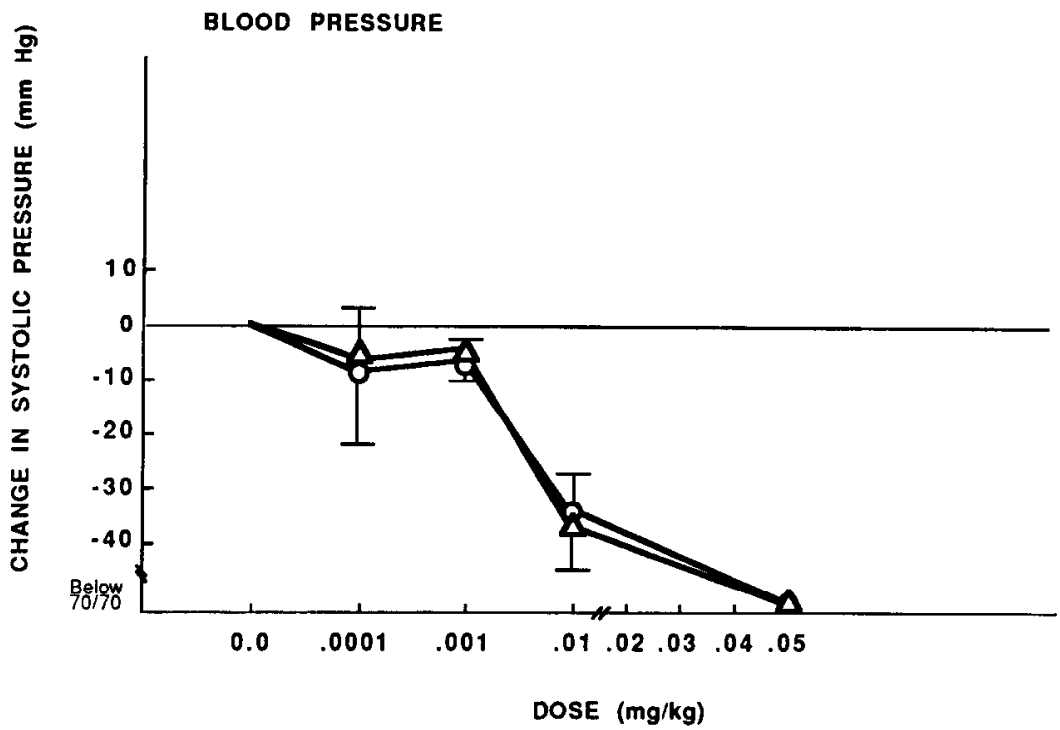

respectively; $0.05 \mathrm{mg} / \mathrm{kg}$ guanfacine vs saline significantly impaired performance: $t$-dep $=3.49, p<0.01]$. At the highest doses tested $(0.5 \mathrm{mg} / \mathrm{kg})$ guanfacine once again improved delayed response performance (Fig. 5). The optimal guanfacine dose for improving delayed response performance was about 25 times lower than the optimal clonidine dose (average guanfacine dose, $0.0016 \pm 0.0011 \mathrm{mg} / \mathrm{kg}$ vs average clonidine dose, 0.039 $\pm 0.0085 \mathrm{mg} / \mathrm{kg}, t$-dep $=4.53, p<0.002$ ). The striking differences between clonidine and guanfacine are evident in the individual dose-response profiles for aged monkeys \#445 (Fig. 3, upper-left-hand graph) and \#1 13 (Fig. 4, middle and top graphs).

Guanfacine's effects on delayed response performance frequently lasted for many days, and improvement in working memory was often seen 3 or $4 \mathrm{~d}$ after guanfacine administration when the animals were tested with saline. This was particularly evident following higher doses of guanfacine (e.g., 0.01-0.05 $\mathrm{mg} / \mathrm{kg}$ ), doses that were often ineffective or impaired delayed response $15 \mathrm{~min}$ after injection. The effects of low doses of guanfacine sometimes lasted up to a week, and occasionally for even longer periods (Fig. 6). Some of these long-lasting drug effects could be accounted for by guanfacine's long half-lifeabout $18 \mathrm{hr}$ (Sorkin and Heel, 1986). However, improvement also persisted beyond the time when drug would be expected to be present in plasma or brain.

Guanfacine produced markedly less sedation than did clonidine (Figs. 3-5); even mild sedation (i.e., sedation score of "I") was not seen until $0.5 \mathrm{mg} / \mathrm{kg}$ of guanfacine. At $0.05 \mathrm{mg} / \mathrm{kg}$ the mcdian sedation scores were "III" for clonidine and " 0 " for guanfacine (Wilcoxon $p<0.008$ ).

Guanfacine was approximately 10 times less potent than clonidine as a hypotensive (Figs. 3, 5). No hypotension was produced in the $0.0001-0.001 \mathrm{mg} / \mathrm{kg}$ range. Indeed, slight hypertension was sometimes observed in this dose range, probably due to stimulation of peripheral alpha- 2 receptors on blood 

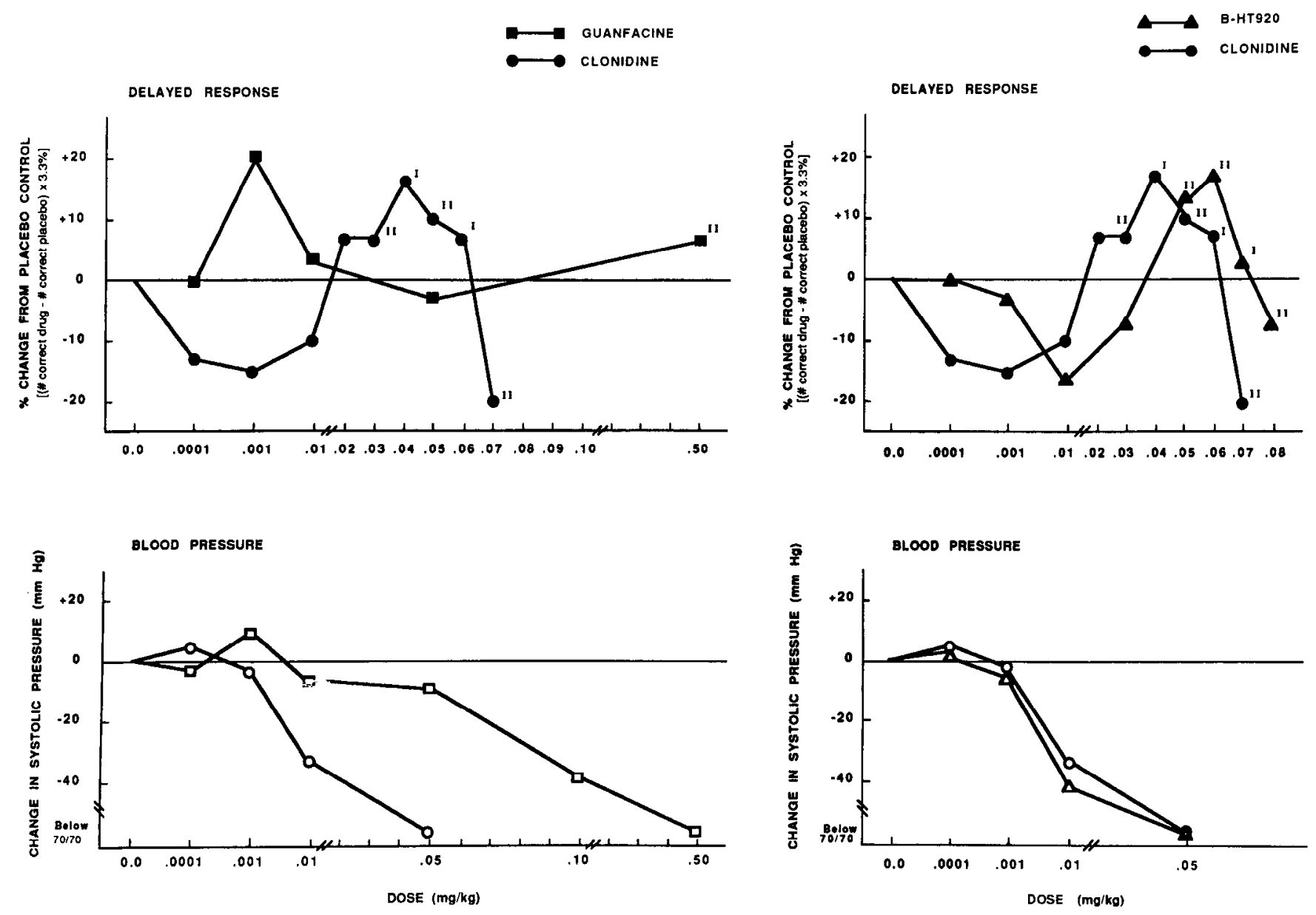

Figure 3. The dose-response profiles of aged monkey \#445 to clonidine (circles), B-HT920 (triangles), and guanfacine (squares). Delayed response performance and sedation data are represented in the top graphs, and systolic blood pressure data in the bottom graphs. Doses of B-HT920 and guanfacine are expressed as equimolar clonidine dosage.

vessels (Scholtysik et al., 1975). Blood pressure began to lower at $0.01 \mathrm{mg} / \mathrm{kg}$, was decreased more substantially at $0.05 \mathrm{mg} / \mathrm{kg}$, and was below $70 / 70 \mathrm{~mm}$ following administration of $0.5 \mathrm{mg} /$ $\mathrm{kg}$ guanfacine.

\section{Idazoxan reversal of the guanfacine response}

We previously showed that clonidine's beneficial effects on delayed response performance could be blocked by the alpha-2 antagonist, yohimbine (Arnsten and Goldman-Rakic, 1985). To determine whether guanfacine's effects were likewise mediated by alpha- 2 receptors, we tested the ability of the alpha- 2 antagonist idazoxan $(0.1 \mathrm{mg} / \mathrm{kg})$ to reverse the low-dose guanfacine response. As can be seen in Figure 7, idazoxan $(0.1 \mathrm{mg} / \mathrm{kg})$ significantly reversed the facilitory effects of low doses of guanfacine on delayed response performance: average guanfacine response, $+14.0 \%$; average guanfacine + idazoxan response, $-5.6 \%$, both compared with saline control; guanfacine vs guanfacine + idazoxan $(t$-dep $=10.11, p<0.001)$. Thus, as with clonidine, guanfacine's beneficial effects appear to result from actions at alpha- 2 adrenergic receptors.

\section{Summary}

Low doses of clonidine impaired, while low doses of guanfacine improved, delayed response performance (Fig. 8). At higher doses (e.g., $0.05 \mathrm{mg} / \mathrm{kg}$ ), the opposite dose-response profiles were seen: clonidine improved, while guanfacine impaired, delayed response performance (Fig. 8). B-HT920 produced a doseresponse profile qualitatively similar to, but weaker than, clonidine (Fig. 8). Thus, the order of potency for improving delayed response performance was guanfacine $>$ clonidine $>$ B-HT920, while the order for inducing delayed response impairment was clonidine > B-HT920 > guanfacine. The ability to produce sedation or hypotension showed the same order of potency as that to induce delayed response impairment: clonidine $\geq$ B-HT920 > guanfacine.

\section{Discussion}

The present study compared the effects of the alpha-2 agonists clonidine, B-HT920, and guanfacine on blood pressure, sedation, and working memory, the latter as measured by performance on the delayed response task. In a low to moderate dose range, guanfacine and clonidine exhibited opposite dose-response curves, while B-HT920 produced a profile qualitatively similar to, but often weaker than, clonidine. Thus, low doses of clonidine or B-HT920 impaired delayed response performance, lowered blood pressure, and began to induce sedation, while low doses of guanfacine significantly improved delayed response scores without inducing any hypotension or sedation. At higher doses, the responses were reversed: guanfacine impaired delayed 

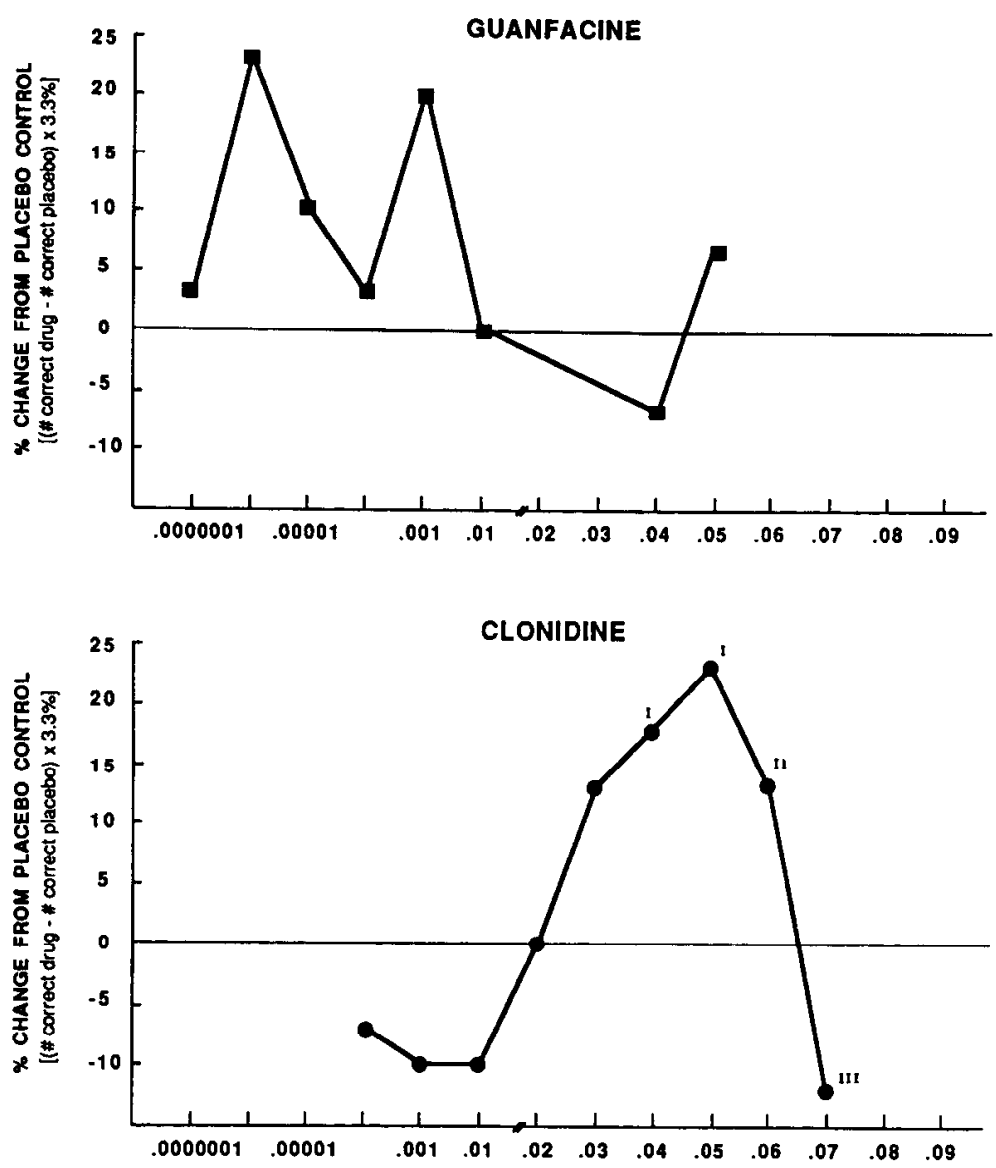

Figure 4. Effects of guanfacine (top graph), clonidine (middle graph), and B-HT920 (bottom graph) on delayed response performance and sedation in aged monkey \#113. Doses of B-HT920 and guanfacine are expressed as equimolar clonidine dosage.

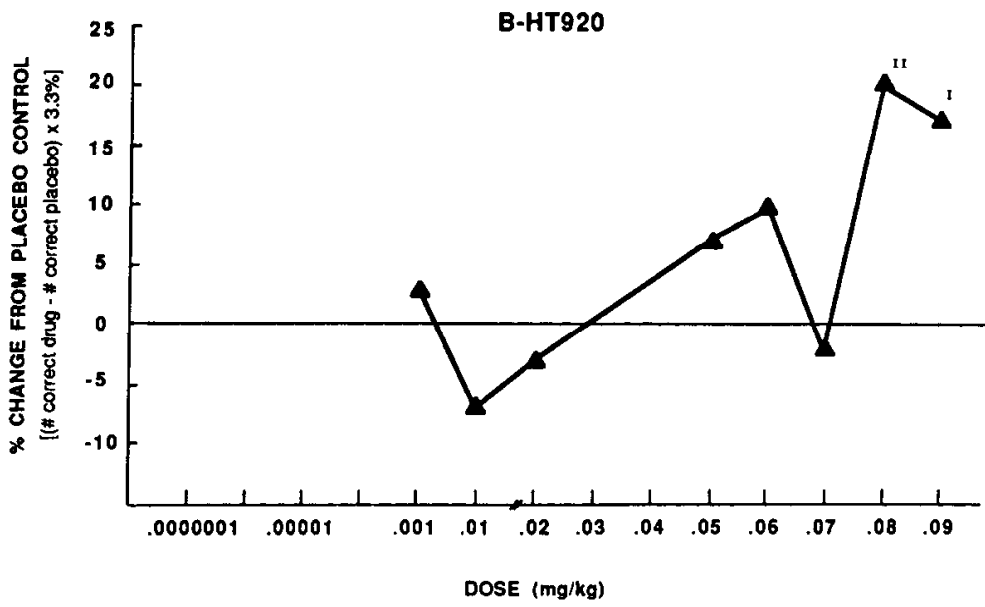

response and began to lower blood pressure, while clonidine and B-HT920 improved performance on delayed response. The hypotensive and sedative effects of clonidine and B-HT920 were very marked in this dose range, and at still higher doses the animals became too sedated to test. Likewise, at the very highest doses of guanfacine tested, blood pressure dropped markedly, sedation became evident, and delayed response scores were once again improved. Thus, in the low to moderate dose range, guanfacine and clonidine exhibited opposite dose-response profiles, but at the highest doses, all alpha- 2 agonists produced qualitatively similar effects. Guanfacine was approximately 25 times more potent than clonidine in enhancing delayed response performance and about 10 times less potent in lowering blood pressure.

Our results of alpha-2 agonist effects on blood pressure in aged monkeys are in agreement with findings in rats (Saameli et al., 1975) and humans (Kugler et al., 1980). In these studies, guanfacine is reported to be 10 times less potent than clonidine. 

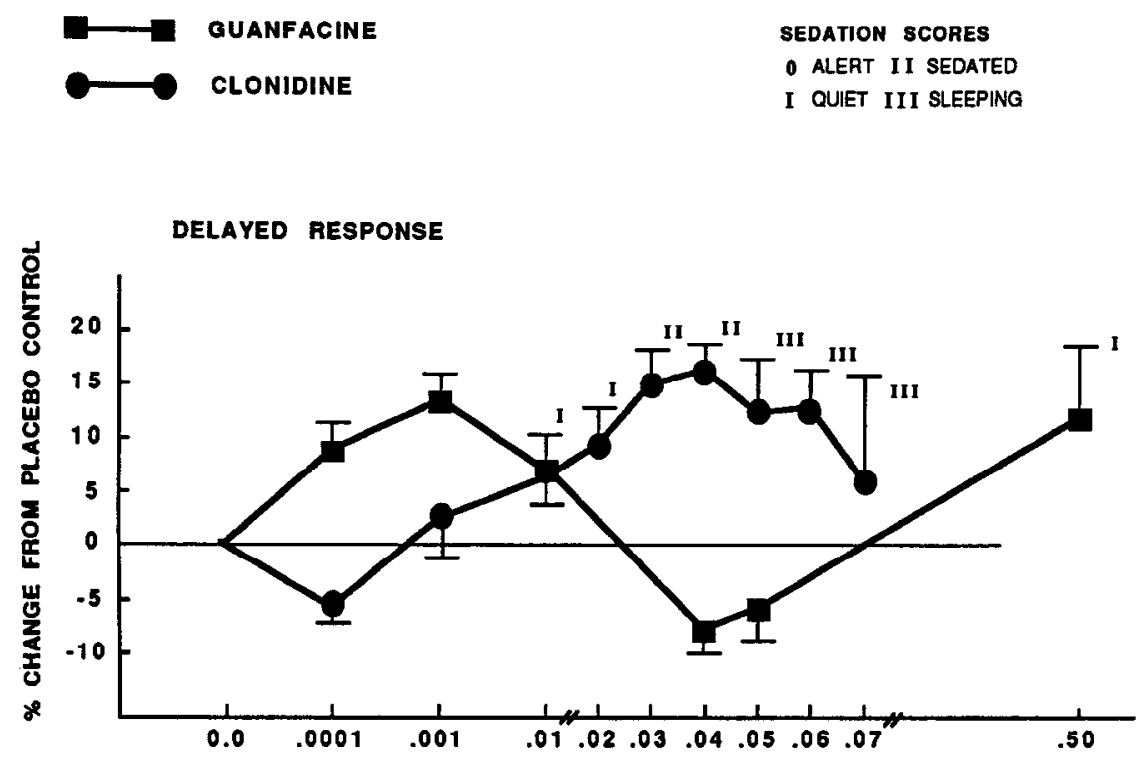

BLOOD PRESSURE

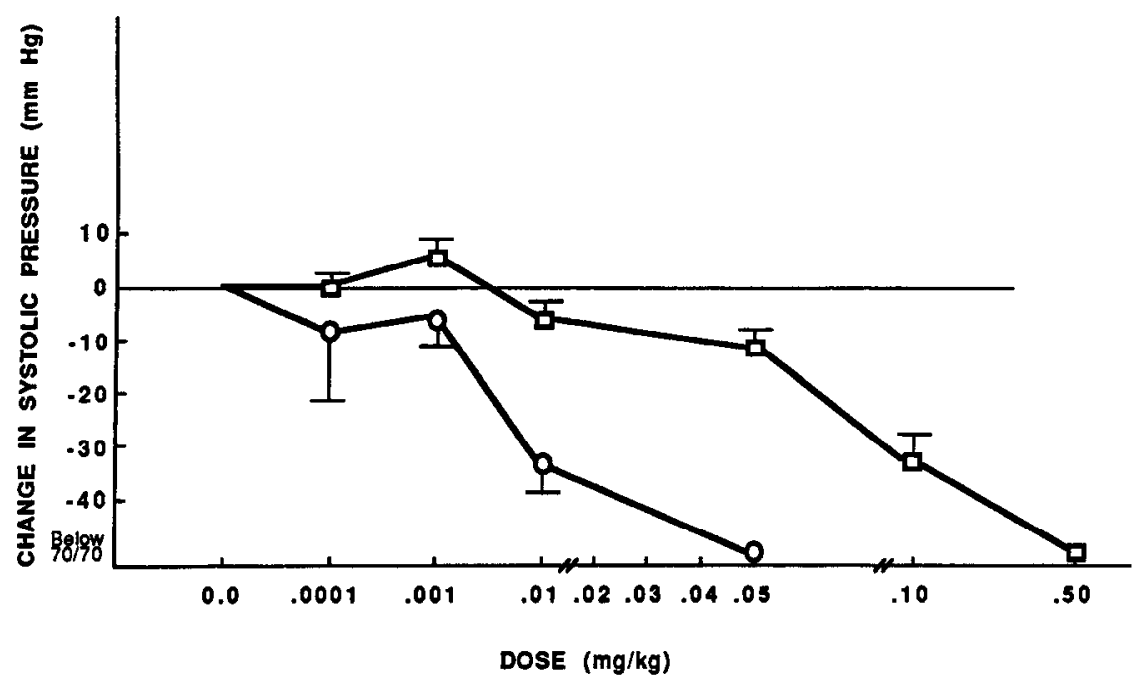

SEDATION SCORES

O ALERT II SEDATED

I QUIET III SLEEPING

Figure 5. Effects of clonidine (circles) and guanfacine (squares) on delayed response performance and sedation (top graph, $n=9$ ) and systolic blood pressure (bottom graph, $n=3$ ). Data points represent means $\pm \mathrm{SEM}$; guanfacine doses are expressed as equimolar clonidine dosage.

Guanfacine is also reported to be much less sedating than clonidine as measured by EEG recordings in humans (Kugler et al., 1980) and rats (Kleinlogel et al., 1975; Saameli et al., 1975) and by self-report rating scales in humans (Kugler et al., 1980). For example, young adult human volunteers administered low doses of clonidine (about $0.004 \mathrm{mg} / \mathrm{kg}$ ) rated themselves as apathetic and reluctant to work, whereas volunteers administered an equihypotensive dose of guanfacine (about $0.04 \mathrm{mg} / \mathrm{kg}$ ) did not report these sedating effects. The aged monkcys were similarly less sedated at equihypotensive doses. Thus, the median sedation score for $0.05 \mathrm{mg} / \mathrm{kg}$ clonidine was "III" (intermittent sleeping), while the median sedation score for an equihypotensive dose $(0.50 \mathrm{mg} / \mathrm{kg})$ of guanfacine was "I" (quiet).

Little clinical research has been done on the cognitive effects of alpha-2 agonists; however, available data are consonant with the present findings in the aged monkeys. Although no study examined dose-response profiles in any single group of subjects, low doses of clonidine (about $0.004 \mathrm{mg} / \mathrm{kg}$ ) have been reported to impair performance on tasks requiring concentration (Kugler et al., 1980) and on paired associative learning (Frith et al., 1985 ) in young adult volunteers, while higher clonidine doses (chronic administration of about $0.01 \mathrm{mg} / \mathrm{kg}$ ) have been found to improve measures of memory and attention in Korsakoff's patients with cognitive deficits and NE loss (McEntee and Mair, 1980; Mair and McEntee, 1986). The one study on the cognitive effects of guanfacine that we are awarc of compared guanfacine (about $0.04 \mathrm{mg} / \mathrm{kg}$ ) with an equihypotensive dose of clonidine (about $0.004 \mathrm{mg} / \mathrm{kg}$ ) in normal young adult volunteers (Kugler et al., 1980). Unfortunately, there was no saline control group, and thus one can conclude only that guanfacine was significantly less deleterious than was clonidine on measures of reaction time and concentration. Guanfacine has also been reported to be less potent than clonidine in inhibiting morphine withdrawal signs (van der Laan, 1985) and in suppressing accompanying in- 

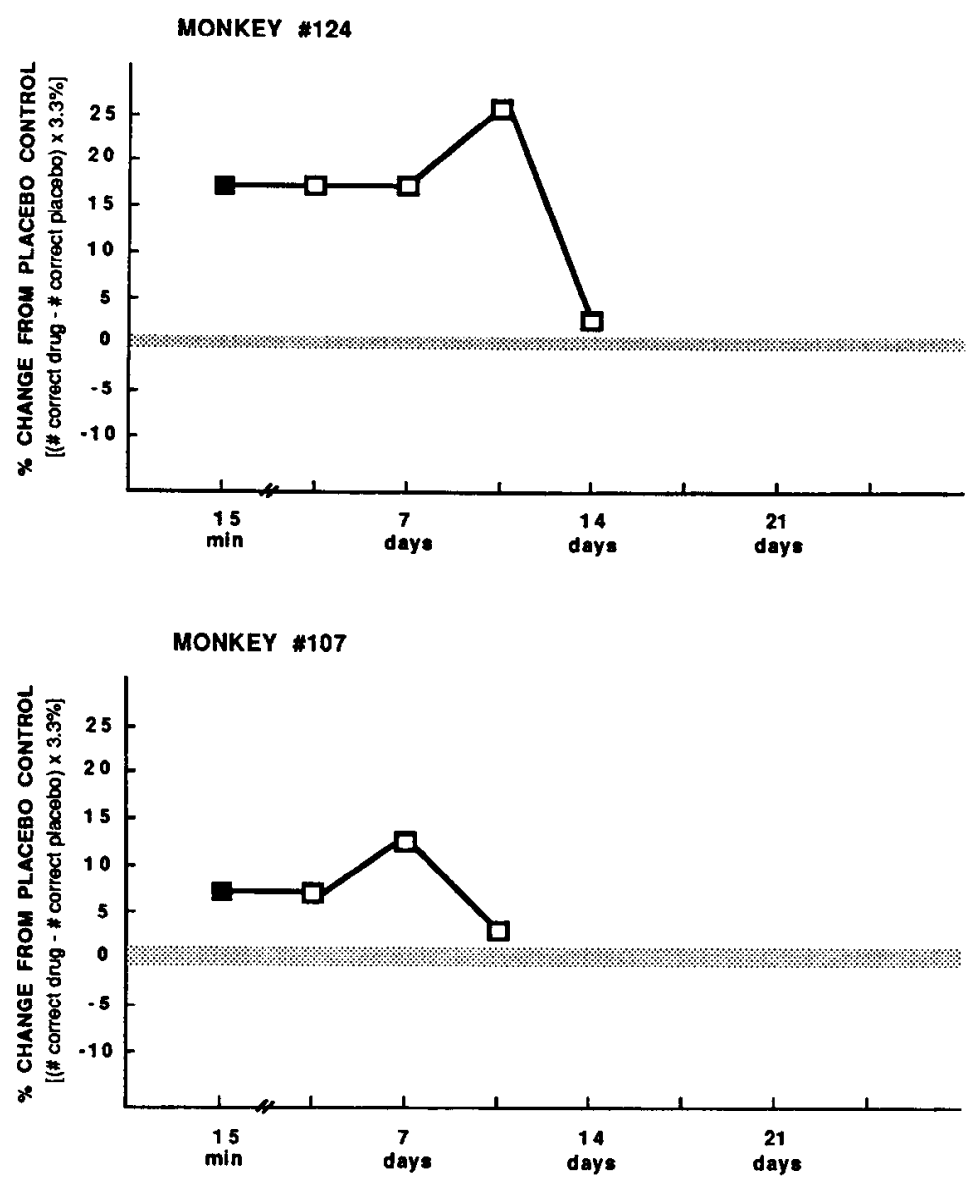

Figure 6. Examples of the long-lasting effects of a single injection of guanfacine on delayed response performance in 3 aged monkeys (top graph: monkey \#124, $0.0001 \mathrm{mg} / \mathrm{kg}$ guanfacine; middle graph: monkey $\# 107,0.00001 \mathrm{mg} / \mathrm{kg}$ guanfacine; bottom graph: monkey \#343, 0.01 $\mathrm{mg} / \mathrm{kg}$ guanfacine). Solid squares indicate guanfacine administration; open squares indicate subsequent saline administration. Animals were tested twice a week, 15 min after drug or saline injection. Shaded line represents the variability $( \pm S E M)$ in baseline (placebo control) performance for each individual animal (\#124: $\pm 0.8 \%$; \#107: $\pm 1.1 \%$; \#343: $\pm 0.3 \%$ ).

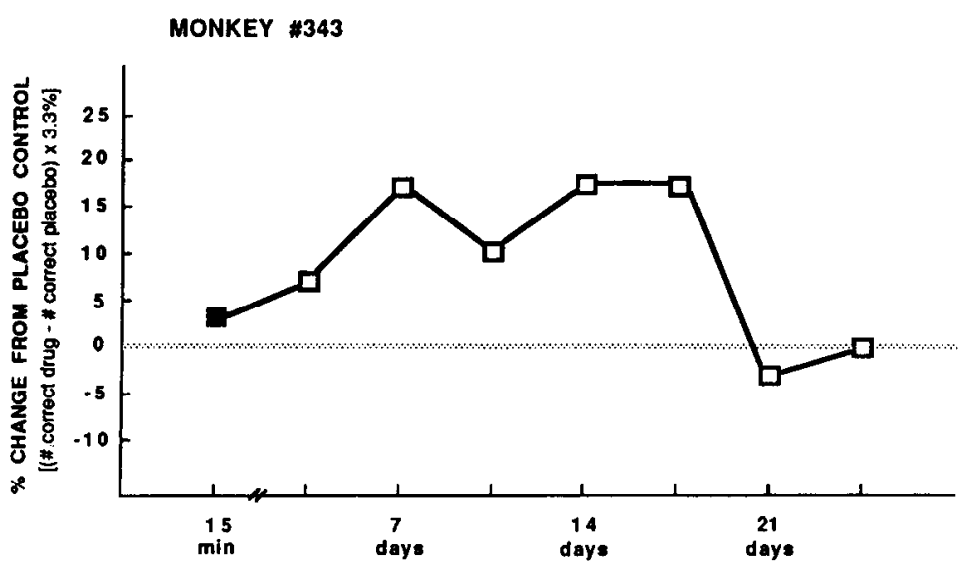

TIME AFTER GUANFACINE INJECTION

creased NE turnover in rats (Zigun et al., 1981). In general, researchers have speculated that guanfacine's weaker effects result from decreased efficacy at the alpha-2 receptor (Summers et al., 1981).

Although there are many examples in the literature demonstrating that guanfacine is less potent than clonidine, this is the first report of a more potent response with guanfacine than clonidine. The ability of guanfacine to improve delayed response performance at very low doses argues that its weaker effects on blood pressure and sedation cannot be due to poorer entry into the CNS nor to poorer efficacy at a homogeneous population of alpha- 2 receptors. Nor can the differences in dose-response pro- files be accounted for by known interactions with non-alpha-2 receptors. For example, clonidine has some agonist actions at alpha- 1 receptors. However, as both guanfacine and B-HT920 have lower affinity for alpha-1 receptors than does clonidine (Doxey, 1979; Kobinger, 1986), alpha-1/alpha-2 efficacy cannot account for the finding that guanfacine exhibits an opposite dose-response profile from clonidine and B-HT920. B-HT920 is known to stimulate dopamine autoreceptors (D2 receptors; Anden et al., 1982), but since clonidine does not act at these receptors (Aghajanian and Bunney, 1977), this mechanism cannot explain the differences between guanfacine and the other 2 compounds. 


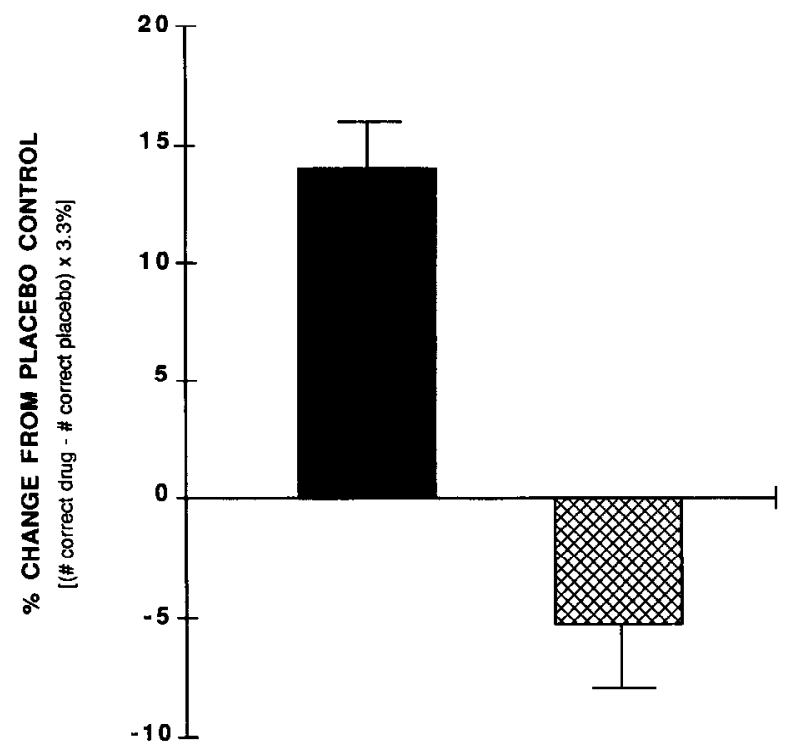

GUANFACINE

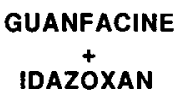

Figure 7. Effects of the alpha-2 antagonist idazoxan $(0.1 \mathrm{mg} / \mathrm{kg})$ on guanfacine's ability to improve delayed response performance. Bars represent means \pm SEM for 5 aged monkeys.

\section{Evidence for actions at alpha-2 receptors}

A preponderance of evidence indicates that the hypotensive effects of clonidine, B-HT920, and guanfacine result from actions at alpha-2 receptors (Schmitt et al., 1971; Scholtysik et al., 1975; Thoolen et al., 1983; Kobinger, 1986), as do the sedating effects of these agonists (Drew et al., 1979). The present study, as well as previous data from this laboratory, suggest that the memory-altering properties of these drugs also arise from actions at alpha- 2 receptors. Thus, both guanfacine's and clonidine's beneficial effects on memory have been blocked by alpha- 2 antagonists (Arnsten and Goldman-Rakic, 1985, and present study), while an alpha-1 antagonist was ineffective in this regard (Arnsten and Goldman-Rakic, 1985). Furthermore, the finding that all 3 alpha-2 agonists examined were capable of improving delayed response performance supports our interpretation that spatial working memory in the primate involves alpha- 2 adrenergic mechanisms. As the hypotensive, sedating, and memory-altering properties of clonidine, B-HT920, and guanfacine all appear to involve actions at alpha-2 receptors, the striking differences in the dose-response profiles produced by the 3 agonists could be explained through an alpha- 2 mechanism.

\section{Alpha-2 receptor subtypes hypothesis}

An hypothesis that can explain guanfacine's and clonidine's contrasting dose-response curves is that these agonists are acting differentially at subtypes of alpha-receptors. Although there is general agreement that alpha-2 rcceptors exhibit complcx binding characteristics, some disagreement exists as to whether receptor subtypes are responsible for this heterogeneity. For example, several groups have provided evidence for low- and high-affinity states of a single receptor, one state with high affinity for agonists and the other for antagonists (Asakura et al., 1984; U'Prichard et al., 1986). However, other binding experiments have yielded results consistent with the existence of distinct subtypes of alpha-2 receptors (e.g., Cheung et al., 1982;
CLONIDINE

D-HT920

GUANFACINE

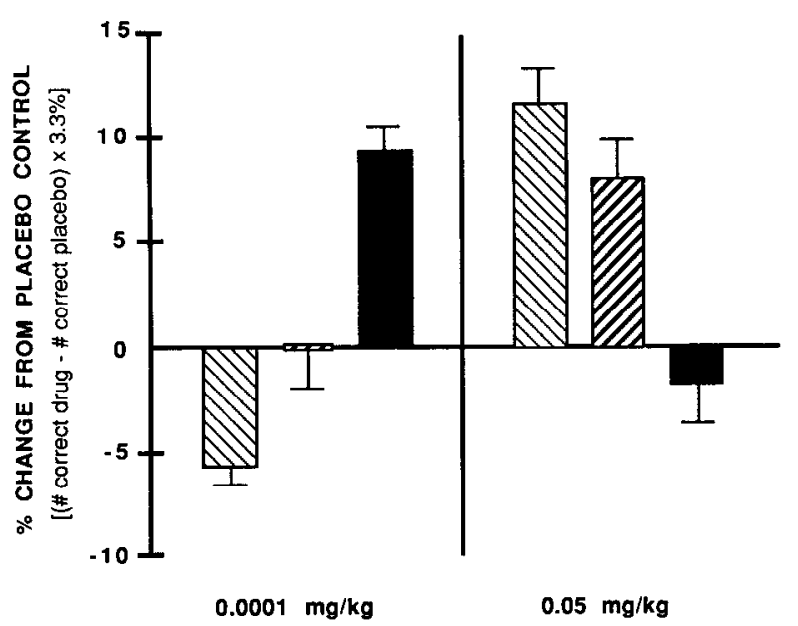

Figure 8. Effects of 0.0001 and $0.05 \mathrm{mg} / \mathrm{kg}$ clonidine $(n=9)$, B-HT920 $(n=6)$, and guanfacine $(n=9)$ on delayed response performance. Bars represent means \pm SEM. Doses are equimolar clonidine dosage.

Bylund, 1985; Boyajian and Leslie, 1987). The recent cloning and sequencing of the alpha-2 receptor from human platelet has also yielded evidence compatible with the concept of alpha-2 receptor subtypes (Kobilka et al., 1987). The classification scheme for alpha-2 receptor subtypes most amenable to behavioral pharmacological testing is that a rauwolscine-sensitive site (Rs) binds both rauwolscine and idazoxan, and a rauwolscine-insensitive site (Ri) binds idazoxan only (Boyajian and Leslie, 1987). As would be expected of receptor subtypes, the Rs and $\mathrm{Ri}$ binding sites are localized in different regions of the brain or kidney (Boyajian et al., 1987) and exhibit distinct pharmacological profiles (Boyajian and Leslie, 1987). However, although Rs and Ri have individual binding profiles, both display the characteristics of alpha-2 receptors and do not share the properties of other adrenergic, dopaminergic, or serotonergic receptors (Boyajian and Leslie, 1987). Clonidine, B-HT920 and guanfacine have distinctly different binding profiles at the 2 sites. The Rs site binds clonidine $>$ B-HT920 > guanfacine, with $K_{i}$ values of $27.7,62.2$, and $340.0 \mathrm{nM}$, respectively. The Ri site binds guanfacine $>$ clonidine $>$ B-HT920, with respective $K_{i}$ values of 22.6, 38.1, and $138.0 \mathrm{~nm}$.

The present study revealed an excellent correlation between an agonist's ability to displace idazoxan and its ability to improve delayed response performance: guanfacine $>$ clonidine $>$ B-HT920. Furthermore, the only drug with high selectivity for the $\mathrm{Ri}$ site, guanfacine, was the only agent to produce a robust delayed response improvement without hypotensive or sedative side effects. There was also a good correlation between thc ability to displace rauwolscine and the dose needed to impair delayed response or produce sedation: clonidine $>$ B-HT920 > guanfacine. The correlation between the ability to displace rauwolscine and the ability to lower blood pressure was not quite as good: clonidine $=\mathrm{B}-\mathrm{HT} 920>$ guanfacine. B-HT920 is the most selective agonist at the Rs site, but nonetheless its affinity is much lower than clonidine. Its ability to lower blood pressure with equal potency in this study might have a number of explanations. In addition to its selectivity for the Rs site, its actions 
at D2 receptors may contribute to its hypotensive effects (Hahn et al., 1983), or it is possible that the hypotensive actions of alpha-2 agonists may be governed by an as yet unidentified alpha-2 subtype. Alternatively, B-HT920's equipotent hypotensive actions in the aged monkey may be exceptional, as it is reported to be 5 times weaker than clonidine in lower animals (Hoefke and Jennewein, 1981). In support of a relationship between the Rs site and hypotension is the interesting observation that guanfacine is 10 times weaker than clonidine in both its ability to displace rauwolscine and in its ability to lower blood pressure.

In summary, the present study demonstrated that the potency of an alpha-2 agonist to improve memory correlated with its ability to displace idazoxan (affinity for the putative Ri subtype), while potency to produce memory impairment, sedation, and to some extent hypotension, correlated with an agonist's ability to displace rauwolscine (affinity for the putative Rs subtype). These data are consonant with the findings of Boyajian et al. (1987) and strongly support the existence of alpha-2 receptor subtypes.

\section{Speculation on pre- versus postsynaptic localization}

For over 50 years it has been known that the dorsolateral region of the prefrontal cortex is essential for performance of the delayed response task (Jacobsen, 1936). More recent studies have localized the area critical for this function to the cortex surrounding the principal sulcus (Goldman and Rosvold, 1970; for review, see Goldman-Rakic, 1987). Data from young monkeys with 6-OHDA-lesions restricted to the principal sulcal cortex indicate that alpha-2 agonists improve delayed response performance, at least in part, through actions at postsynaptic receptors in this cortical region (Brozoski et al., 1979; Arnsten and Goldman-Rakic, 1985). The current results link memory improvement to the putative Ri receptor subtype, thus suggesting that $\mathrm{Ri}$ receptors would be located postsynaptically in cortex. Conversely, if memory impairment results from inhibition of the NE system through actions at alpha-2 autoreceptors, then presynaptic receptors may be of the putative Rs subtype. However, the Rs site might also be located postsynaptically, as the sedative and hypotensive effects of alpha- 2 agonists are thought to be mediated at postsynaptic receptors. Support for this hypothesis can be found in biochemical and receptor binding studies. For example, the majority of idazoxan binding in the cortex has been found to be postsynaptically located in rats treated with the NE neurotoxins DSP-4 or 6-OHDA (Pimoule et al., 1983), and there are more high-affinity guanfacine than high-affinity clonidine binding sites in rat cortex (Summers et al., 1981). Furthermore, the agonist with high selectivity for the $\mathrm{Ri}$ site, guanfacine, is much less potent than is clonidine in decreasing NE turnover in rat brain (Scholtysik et al., 1975) or human plasma (Kugler et al., 1980), indicating that guanfacine is less active at presynaptic receptors than is clonidine. Indeed, guanfacine is about 10 times less potent than is clonidine both in decreasing NE turnover (Scholtysik et al., 1975) and in displacing rauwolscine binding, consistent with the presynaptic alpha- 2 receptor being of the Rs type. However, this hypothesis does not explain the finding that the distribution of high-affinity rauwolscine binding sites in the brain does not follow that of $\mathrm{NE}$ as would be expected with a presynaptic NE receptor (Boyajian et al., 1987). Indeed, the areas most densely labeled by rauwolscine are often low in NE and high in dopamine, e.g., the striatum (Boyajian et al., 1987). Possibly, this may be due to rauwolscine labeling the antagonist state of the receptor. Alter- natively, the ability of an agonist to displace rauwolscine may correlate with affinity at some other site subserving memory impairment. The cellular localization of these putative receptor subtypes should be examined directly by observing changes in tritiated guanfacine or rauwolscine binding following destruction of the NE system.

\section{Long-lasting effects of guanfacine: possible mechanisms}

Guanfacine occasionally produces very long-lasting improvements in memory which persist after the drug presumably is catabolized and excreted. These long-lasting responses are suggestive of drug actions at a second-messenger system. In many type of cells, including LC neurons, alpha- 2 receptors have been found to be negatively coupled to adenylate cyclase, and clonidine can be a potent inhibitor of cAMP production (Sabol and Nirenberg, 1979; Andrade and Aghajanian, 1985). However, alpha-2 receptor stimulation has also been found to increase cAMP levels in rat cortex, by enhancing the effects of beta noradrenergic agonists and other hormones (Pilc and Enna, 1986). Interestingly, this enhancement is more potently blocked by idazoxan than by rauwolscine (Pilc and Enna, 1986). Furthermore, clonidine is not very potent in facilitating hormoneinduced cAMP production. The present results in aged monkeys suggest that low concentrations of guanfacine may be poor inhibitors of cAMP production in the LC, but may enhance hormone-stimulated cAMP production in cortex. It is tempting to speculate that this latter mechanism may be related to guanfacine's long-lasting beneficial effects on delayed response performance.

\section{Clinical relevance}

The ability of low doses of guanfacine to improve working memory without sedative or hypotensive side effects indicates it would be an excellent candidate for clinical trials in normal elderly with age-related cognitive decline ("age-associated memory impairment") or in patients with memory disorder associated with NE loss, such as Alzheimer's, Korsakoff's, or Parkinson's diseases. In Korsakoff's syndrome, memory impairment has been correlated with indices of NE loss (McEntee and Mair, 1978), and Korsakoff patients have been significantly improved by chronic treatment with relatively high doses of clonidine (McEntee and Mair, 1980; Mair and McEntee, 1986). In Alzheimer's disease, there is extensive deterioration of the LC (Forno, 1978; Tomlinson et al., 1981; Iversen et al., 1983), particularly the anterior portion (German et al., 1987) innervated by the prefrontal cortex (Arnsten and Goldman-Rakic, 1984), and a corresponding loss of NE in the frontal and temporal cortices (Adolfsson et al., 1979; Cross et al., 1981; Perry et al., 1981; Benton et al., 1982; Iversen et al., 1983). However, alpha-2 receptors are not diminished in cortex (Cross et al., 1984; Shimohama et al., 1986), suggesting that the postsynaptic element remains a viable target for alpha-2 agonists. Thus, stimulation of these receptors with the alpha-2 agonist guanfacine might provide effective adrenergic replacement therapy, improving cognition without producing the severe sedative and hypotensive side effects so prevalent with clonidine administration.

\section{References}

Adolfsson, R., C. G. Gottfries, B. E. Roos, and B. Winblad (1979) Changes in the brain catecholamines in patients with dementia of Alzheimer type. Br. J. Psychiatry 135: 216-223.

Aghajanian, G. K., and B. S. Bunney (1977) Dopamine "autorecep- 
tors": Pharmacological characterization by microiontophoretic single cell recording studies. Naunyn Schmiedebergs Arch. Pharmacol. 297: $1-7$.

Anden, N.-E., K. Golembiowska-Nikitin, and U. Thornstom (1982) Selective stimulation of dopamine and noradrenaline autoreceptors by B-HT920 and B-HT933, respectively. Naunyn Schmiedebergs Arch. Pharmacol. 321: 100-104.

Andrade, R., and G. K. Aghajanian (1985) Opiate- and alpha-2-adrenoceptor-induced hyperpolarizations of locus coeruleus neurons in brain slices: Reversal by cyclic adenosine $3^{\prime}: 5^{\prime}$-monophosphate analogues. J. Neurosci. 5: 2359-2364.

Arnsten, A. F. T., and P.S. Goldman-Rakic (1984) Selective prefrontal cortical projections to the region of the locus cocrulcus and raphe nuclei in the rhesus monkey. Brain Res. 306: 9-18.

Arnsten, A. F. T., and P. S. Goldman-Rakic (1985) Alpha-2 adrenergic mechanisms in prefrontal cortex associated with cognitive decline in aged nonhuman primates. Science 230: 1273-1276.

Asakura, M., T. Tsukamoto, J. Imafuku, H. Matsui, M. Ino, and K. Hasegawa (1984) Quantitative analysis of rat brain alpha-2 receptors discriminated by $[3 \mathrm{H}]$ clonidine and $[3 \mathrm{H}]$ rauwolscine. Eur. J. Pharmacol. 106: 141-147.

Benton, J. S., D. M. Bowen, S. J. Allen, E. A. Haan, A. N. Davison, D. Neary, R. P. Murphy, and J. S. Snowden (1982) Alzheimer's disease as a disorder of isodendritic core. Lancet 2-I: 456.

Boyajian, C. L., and F. M. Leslie (1987) Pharmacological evidence for alpha-2-adrenoceptor heterogeneity: Differential binding properties of $[3 \mathrm{H}]$ rauwolscine and $[3 \mathrm{H}]$ idazoxan in rat brain. J. Pharmacol. Exp. Ther. 241: 1092-1098.

Boyajian, C. L., S. E. Loughlin, and F. M. Leslie (1987) Anatomical evidence for alpha-2-adrenoceptor heterogeneity: Differential autoradiographic distributions of $[3 \mathrm{H}]$ rauwolscine and $[3 \mathrm{H}]$ idazoxan in rat brain. J. Pharmacol. Exp. Ther. 241: 1079-1091.

Brozoski, T., R. M. Brown, H. E. Rosvold, and P. S. Goldman (1979) Cognitive deficit caused by regional depletion of dopamine in prefrontal cortex of rhesus monkey. Science 205: 929-931.

Bylund, D. B. (1985) Heterogeneity of alpha-2 adrenergic receptors. Pharmacol. Biochem. Behav. 22: 835-843.

Carli, M., T. W. Robbins, J. L. Evenden, and B. J. Everitt (1983) Effects of lesions to ascending noradrenergic neurones on performance of a 5-choice serial reaction task in rats; Implications for theories of dorsal noradrenergic bundle function based on selective attention and arousal. Behavioral Brain Res. 9: 361-380.

Cedarbaum, J. M., and G. K. Aghajanian (1976) Noradrenergic neurons of the locus coeruleus: Inhibition by epinephrine and activation by the alpha-antagonist piperoxane. Brain Res. 112: 413-419.

Cheung, Y.-D., D. B. Barnett, and S. R. Nahorski (1982) [3H] rauwolscine and $[3 \mathrm{H}]$ yohimbine binding to rat cerebral and human platelet membranes: Possible heterogeneity of alpha-2-adrenoceptors. Eur. J. Pharmacol. 84: 79-85.

Corkin, S. (1982) Some relationships between global amnesias and the memory impairments in Alzheimer's disease. In Alzheimer's Disease: A Report of Progress (Aging), Vol. 19, S. Corkin, K. L. Davis, J. H. Growdon, E. Usdin, and R. J. Wurtman, eds., pp. 149-164, Raven, New York.

Cross, A. J., T. J. Crow, E. K. Perry, R. H. Perry, G. Blessed, and B. E. Tomlinson (1981) Reduced dopamine-beta-hydroxylase activity in Alzheimer's disease. Br. Med. J. 282: 93-94.

Cross, A. J., T. J. Crow, J. A. Johnson, E. K. Perry, R. H. Perry, G. Blessed, and B. E. Tomlinson (1984) Studies on neurotransmitter receptor systems in neocortex and hippocampus in senile dementia of the Alzheimer's type. J. Neurol. Sci. 64: 109-117.

Dollery, C. T., D. S. Davies, G. H. Draffan, H. J. Dargie, C. R. Dean, J. L. Reid, R. A. Clare, and S. Murray (1976) Clinical pharmacology and pharmacokinetics of clonidine. Clin. Pharmacol. Ther. 19: 1117.

Doxey, J. C. (1979) Pre- and postsynaptic effects of alpha-agonists in the anococcygeus muscle of the pithed rat. Eur. J. Pharmacol. 54: 185-189.

Drew, G. M., A. J. Gower, and A. S. Marriott (1979) Alpha-2 adrenoreceptors mediate clonidine-induced sedation in the rat. Br. J. Pharmacol. 67: 133-141.

Foote, S. L., R. Freedman, and A. P. Oliver (1975) Effects of putative neurotransmitters on neuronal activity in monkey auditory cortex. Brain Res. 86: 229-242.

Forno, L. S. (1978) The locus coeruleus in Alzheimer's disease. Neuropathol. Exp. Neurol. 37: 614.

Friedman, H. R., and P. S. Goldman-Rakic (1988) Activation of the hippocampus by working memory: A 2-deoxyglucose study of behaving rhesus monkeys. J. Neurosci. (in press).

Frith, C. D., J. Dowdy, I. N. Ferrier, and T. J. Crow (1985) Selective impairment of paired associate learning after administration of a centrally-acting adrenergic agonist (clonidine). Psychopharmacology 87: $490-493$.

German, D. C., C. L. White, and D. R. Sparkman (1987) Alzheimer's disease: Neurofibrillary tangles in nuclei that project to the cerebral cortex. Neuroscience 21: 305-312.

Goldman, P. S., and H. E. Rosvold (1970) Localization of function within the dorsolateral prefrontal cortex of the rhesus monkey. Exp. Neurol. 27: 291-304.

Goldman-Rakic, P.S. (1987) Circuitry of the primate prefrontal cortex and the regulation of behavior by representational memory. In Handbook of Physiology. The Nervous System, Higher Functions of the Brain, Sect. I, Vol. V, Pt. 1, F. Plum, ed., pp. 373-417, American Physiological Society, Bethesda, MD.

Goldman-Rakic, P. S., and R. M. Brown (1981) Regional changes of monoamines in cerebral cortex and subcortical structures of aging rhesus monkeys. Neuroscience 6: 177-187.

Hahn, R. A., B. R. McDonald, and M. A. Martin (1983) Antihypertensive activity of LY141865, a selective presynaptic dopamine receptor agonist. J. Pharmacol. Exp. Ther. 224: 206-214.

Hoefke, W., and H. M. Jennewein (1981) Mechanisms of antihypertensive action of clonidine in relation to its psychotropic effects. In Psychopharmacology of Clonidine, pp. 75-97, Liss, New York.

Iversen, L. L., M. N. Rossor, G. P. Reynolds, R. Hills, M. Roth, C. Q. Mountjoy, S. L. Foote, J. H. Morrison, and F. E. Bloom (1983) Loss of pigmented dopamine-beta-hydroxylase positive cells from locus coeruleus in senile dementia of Alzheimer's type. Neurosci. Lett. 39: 95-100.

Jacobsen, C. F. (1936) Studies of cerebral function in primates. Comp. Psychol. Monogr. 13: 1-68.

Kleinlogel, H., G. Scholtysik, and A. C. Sayers (1975) Effects of clonidine and BS 100-141 on the EEG sleep pattern in rats. Eur. J. Pharmacol. 33: 159-163.

Kobilka, B. K., H. Matsui, T. S. Kobilka, T. L. Yang-Feng, U. Francke, M. G. Caron, R. J. Lefkowitz, and J. W. Regan (1987) Cloning, sequencing, and expression of the gene coding for the human platelet alpha-2-adrenergic receptor. Science 238: 650-656.

Kobinger, W. (1986) Drugs as tools in research on adrenoccptors. Naunyn Schmiedebergs Arch. Pharmacol. 332: 113-123.

Kugler, J., R. Seus, R. Krauskopf, H. M. Brecht, and A. Raschig (1980) Differences in psychic performance with guanfacine and clonidine in normotensive subjects. Br. J. Clin. Pharmacol. 10: 71S-80S.

Lapin, B. A., R. I. Krilova, G. M. Cherkovich, and N. S. Asanov (1979) Observations from Sukhumi. In Aging in Nonhuman Primates, D. M. Bowden, ed., pp. 14-37, van Nostrand Reinhold, New York.

Leslie, F. M., S. E. Loughlin, D. B. Sternberg, J. L. McGaugh, L. E. Young, and S. F. Zornetzer (1985) Noradrenergic changes and memory loss in aged mice. Brain Res. 359: 292-299.

Mair, R. G., and W. J. McEntee (1986) Cognitive enhancement in Korsakoff's psychosis by clonidine: A comparison with l-dopa and ephedrine. Psychopharmacology 88: 374-380.

McEntee, W. J., and R. G. Mair (1978) Memory impairment in Korsakoff's psychosis: A correlation with brain noradrenergic activity. Science 202: 905-907.

McEntee, W. J., and R. G. Mair (1980) Memory enhancement in Korsakoff's psychosis by clonidine: Further evidence for a noradrenergic deficit. Ann. Neurol. 7: 466-470.

McGaugh, J. L., K. C. Liang, C. Bennett, and D. B. Sternberg (1984) Adrenergic influences on memory storage: Interaction of peripheral and central systems. In Neurobiology of Learning and Memory, G. Lynch, J. L. McGaugh, and N. M. Weinberger, eds., pp. 313-332, Guilford, New York.

Oke, A. F., and R. N. Adams (1978) Selective attention dysfunctions in adult rats neonatally treated with 6-hydroxydopamine. Pharmacol. Biochem. Behav. 9: 429-432.

Perry, E. K., B. E. Tomlinson, G. Blessed, R. H. Perry, A. J. Cross, and T. J. Crow (1981) Neuropathological and biochemical observations on the noradrenergic system in Alzheimer's disease. J. Neurol. Sci. 51: 229-237.

Pilc, A., and S. J. Enna (1986) Activation of alpha-2 adrenergic receptors augments neurotransmitter-stimulated cyclic AMP accumulation in rat brain cerebral cortical slices. J. Pharmacol. Exp. Ther. 237: 725-730.

Pimoule, C., B. Scatton, and S. Z. Langer (1983) [3H]RX 781094: A 
new antagonist labels alpha-2-adrenoceptors in the rat brain cortex. Eur. J. Pharmacol. 95: 79-85.

Saameli, K., G. Scholtysik, and R. Waite (1975) Pharmacology of BS 100-141, a centrally acting antihypertensive drug. Clin. Exp. Pharmacol. Physiol. Suppl. 2: 207-212.

Sabol, S. L., and M. Nirenberg (1979) Regulation of adenylate cyclase of neuroblastoma $\times$ glioma hybrid cells by alpha-adrenergic receptors. J. Biol. Chem. 254: 1913-1920.

Schmitt, H., H. Schmitt, and S. Fenard (1971) Evidence for an alphasympathomimetic component in the effect of catapresan on vasomotor centres: Antagonism by piperoxane. Eur. J. Pharmacol. 14: 98-100.

Scholtysik, G., H. Lauener, E. Eichenberger, H. Burki, R. Salzmann, E. Muller-Schweinitzer, and R. Waite (1975) Pharmacological actions of the antihypertensive agent $\mathrm{N}$-amidino-2-(2,6-dichlorophenyl) acetamide hydrochloride (BS 100-141). Drug Res. 25: 1483-1491.

Segal, M., and F. E. Bloom (1976) The action of norepinephrine in the rat hippocampus. IV. The effects of locus coeruleus stimulation on evoked hippocampal unit activity. Brain Res. 107: 513-525.

Shimohama, S., T. Taniguchi, M. Fujiwara, and M. Kameyama (1986) Biochemical characterization of alpha-adrenergic receptors in human brain and changes in Alzheimer-type dementia. J. Neurochem. 47: 1294-1301.

Sorkin, E. M., and R. C. Heel (1986) Guanfacine: A review of its pharmacodynamic and pharmacokinetic properties, and therapeutic efficacy in the treatment of hypertension. Drugs 31: 301-336.
Stein, L., J. D. Belluzzi, and C. D. Wise (1975) Memory enhancement by central administration of norepinephrine. Brain Res. 84: 329-335. Summers, R. J., B. Jarrott, and W. J. Louis (1981) Comparison of $[3 \mathrm{H}]$ clonidine and $[3 \mathrm{H}]$ guanfacine binding to alpha-2 adrenoceptors in membranes from rat cerebral cortex. Neurosci. Lett. 25: 31-36.

Thoolen, M., J. Hendriks, P. Timmermans, and P. van Zweiten (1983) Precipitation by yohimbine of the withdrawal synd romes of clonidine, guanfacine and methyldopa in the spontaneously hypertensive rat. J. Cardiovasc. Pharmacol. 5: 224-228.

Tomlinson, B. E., D. Irving, and G. Blessed (1981) Cell loss in the locus coeruleus in senile dementia of Alzheimer type. J. Neurol. Sci. 49: 419-428.

U'Prichard, D. C., D. J. Loftus, and J. M. Stolk (1986) Functional association between epinephrine neurons and alpha-adrenoceptors in discrete brain areas: Analysis in inbred rat strains. In Neuronal Epinephrine, J. M. Stolk, D. C. U'Prichard, and K. Fuxe, eds., Oxford U. P., New York.

van der Laan, J. W. (1985) Effects of alpha-2 agonists on morphine withdrawal behaviour: Potentiation of jumping mediated by alpha-2 receptors. Naunyn Schmiedebergs Arch. Pharmacol. 329: 293-298.

Zigun, J. R., M. J. Bannon, and R. H. Roth. (1981) Comparison of two noradrenergic agonists (clonidine and guanfacine) on norepinephrine turnover in the cortex of rats during morphine abstinence. Eur. J. Pharmacol. 70: 565-570. 